\title{
The role of imaging studies in critically ill medical patients with mesenteric ischemia
}

\author{
Pantaree Aswanetmanee MD, Chok Limsuwat MD, Ariwan Rakvit MD
}

\section{CASE}

A 75-year-old man with a history of dementia living in a nursing home presented with septic shock with no definite source of infection and acute respiratory failure. He was on a moderate dose of norepinephrine and ventilator support for three days without improvement. His physical examination revealed abdominal distention with decreased bowel sounds. Do we need an abdominal CT scan in this patient?

\section{Discussion}

Imaging studies in critically ill patients in intensive care units help guide treatment. The most widely used radiographic studies that are non-invasive and associated with small or no radiation exposure available at the bedside in the ICU include chest radiography, plain abdominal radiography, and ultrasonography. Plain abdominal films are usually the first imaging studies ordered, are universally available, and are inexpensive ${ }^{1,2}$. However, plain abdominal imaging is rarely helpful in diagnosis and has a low sensitivity and specificity in patients with an acute abdomen ${ }^{3,4}$. Moreover, information obtained by plain abdominal radiography and abdominal ultrasonography in the ICU may be limited by bowel gas, wounds, catheters, tissue defects, and edema ${ }^{5}$. Abdominal imaging with multidetector computed tomography (MDCT) has become the most accurate method to study the abdomen ${ }^{6-8}$. It can be done quickly, and

Corresponding author: Chok Limsuwat, MD Contact Information: Chok.limsuwat@gmail.com DOI: 10.12746/swrccc2013.0104.040 some hospitals have portable CT scans in the ICU. However, the use of abdominal CTs might be limited by the risks associated with patient transfer to the CT scan suite, the high cost, limited availability, and the increased workload of hospital personnel. Moreover, two-thirds of the radiation received by patients who stay in trauma ICUs longer than 30 days is from CT scans, and radiocontrast may cause nephrotoxicity and/or severe allergic reactions ${ }^{9}$. Hence, physicians need to evaluate the risks and benefits before transferring a patient to a CT scan suite. This decision may be difficult in intubated patients and/or patients with polytrauma or hemodynamic compromise, especially in patients with subtle abdominal symptoms, minimal physical findings, or uncertain sites of infection.

There are no randomized controlled trials to delineate how soon, how often, and how helpful CT scans of the abdomen are in clinical decision making in the ICU. Patients with intestinal ischemia can have various clinical presentations which make the diagnosis difficult. We have reviewed recent studies on the role of CT scans of the abdomen in critically ill medical patients with mesenteric ischemia to develop some suggestions for the use of these studies in the ICU.

Acute mesenteric ischemia (AMI) is a life threatening abdominal emergency with mortality rates ranging from 60 to $80 \%{ }^{10-12}$. Mesenteric ischemia is caused by decreased blood flow to the intestine that results in hypoxic injury and then reperfusion damage at the cellular level. These events produce mucosal injury, tissue necrosis, and metabolic acidosis; released toxic metabolites and bacterial translocation contribute to the systemic inflammatory response syndrome and sepsis ${ }^{13}$. The pathophysiology of mesenteric ischemia can be classified into arterial or venous 
etiology and into acute or chronic presentations ${ }^{14}$. An arterial disorder is the more common cause of mesenteric ischemia and has three main mechanisms, including arterial embolism, arterial thrombosis, and non-occlusive hypoperfusion ${ }^{15}$.

The clinical presentation of mesenteric ischemia is non-specific in most cases and can range from minimal clinical findings to severe abdominal pain with metabolic acidosis and shock. Physical examination in mild disease is relatively normal. Increasing abdominal distention, ileus, frank peritonitis, and shock often signify advanced ischemia. Occult blood is detected in up to $50 \%$ of patients; melena and hematochezia occurs in $15 \%$ of cases ${ }^{16}$. However, patients with critical illnesses with advanced intestinal ischemia or necrosis may present with only decreased levels of consciousness, electrolyte abnormalities, and shock. These presentations can make it extremely difficult to establish the diagnosis of mesenteric ischemia.

In critically ill patients abdominal evaluation is needed to determine if the patient has a surgical abdomen and to follow up known intra-abdominal pathology, such as masses, fluid collections, inflammation, and infection. A prospective observational study in a medical-surgical ICU using MDCT in critically ill patients in Finland found that when certain clinical indications are present, $85 \%$ of the MDCT examinations significantly contributed to clinical decision making or suggested new treatment ${ }^{8}$. Since acute mesenteric ischemia can progress rapidly to a fatal disease, prompt diagnosis and treatment are essential to allow effective intervention. A high index of suspicion is the sine qua non for early diagnosis ${ }^{10,17}$.

The laboratory tests in AMI are not sufficient to make a diagnosis. Laboratory results often show leukocytosis, hemoconcentration, metabolic acidosis with a high anion gap, high lactate dehydrogenase, and elevated transaminases. Hyperkalemia and hypophosphatemia may develop in late presentations 18. One small study suggested that serum lactate can help make the diagnosis of AMI. This study found that increased plasma lactate level had a sensitivity of $96 \%$ for recognizing acute mesenteric ischemia in patients with abdominal complaints ${ }^{19}$.

Imaging studies have an important role in the diagnosis of AMI. The information from plain abdominal radiography is generally normal or nonspecific and should not be used to rule out AMI. In late presentations plain films might demonstrate portal venous gas, thumbprinting, or pneumatosis intestinalis 20,21 . Barium enema studies have no role for diagnostic AMI and increase complications ${ }^{21}$. Multidetector CT is a valuable tool for evaluation of mesenteric ischemia since it provides good resolution images of the small bowel and mesenteric vessels ${ }^{22}$. These studies require the rapid injection of contrast with arterial and venous phase images to identify arterial emboli, arterial thrombosis, and venous thrombosis. In addition, the bowel wall should take up contrast, and changes in this pattern helps identify edema, air, and necrosis. The bowel wall is often thin with decreased enhancement during the initial ischemic phase and thicker with edema and intramural hemorrhage during reperfusion, if it occurs. During reperfusion contrast stratification may occur with a hyperenhanced inner layer 23. The presence of pneumatosis intestinal and/or portomesenteric venous gas in patients with clinical presentations consistent with mesenteric ischemia strongly suggests the presence of bowel infarction ${ }^{24}$. Other radiographic findings include intestinal dilation, mesenteric or perienteric fat stranding, pneumoperitoneum, solid organ infarction, and alternative unanticipated diagnoses ${ }^{25-28}$. The sensitivity of MDCT ranges from 96 to $100 \%$ and specificity ranges from 89 to $94 \%$. Mesenteric angiography had been considered to be the investigation of choice in patients who have no immediate indication for emergency laparotomy and can differentiate between thrombotic or embolic causes ${ }^{10}$.

Once the diagnosis of AMI is established, treatment should be initiated immediately and should include fluid resuscitation, parenteral board spectrum antibiotics, analgesics, and surgical consultation. Definitive treatment of AMI depends on the etiology. For acute arterial embolism, options include surgical embolectomy, intra-arterial thrombolysis, and papaverine infusion. For acute arterial thrombosis papaverine infusion and surgical reconstruction are the primary 
approaches to treatment ${ }^{28}$. In non-occlusive mesenteric ischemia, medical management, including papaverine, can help stabilize the patient ${ }^{29}$. However, a patient with an infarcted bowel needs immediate surgery regardless of the underlying pathophysiology. The diagnosis and treatment algorithm are shown in Figure 1. Sepsis and multiple organ dysfunction syndromes occur in many patients with AMI, and the perioperative risk for mortality for revascularization ranges between $44 \%$ to $90 \%{ }^{30,31}$.

\section{Case Conclusion}

Our patient had an abdominal MDCT scan with IV contrast that revealed pneumatosis intestinalis in the jejunum and superior mesenteric artery occlusion. The antibiotics were modified to improve coverage, and he underwent an exploratory laparotomy with small bowel resection and mesenteric artery embolectomy. In this case the MDCT scan led to the correct diagnosis and appropriate surgical management.

\section{Figure 1}

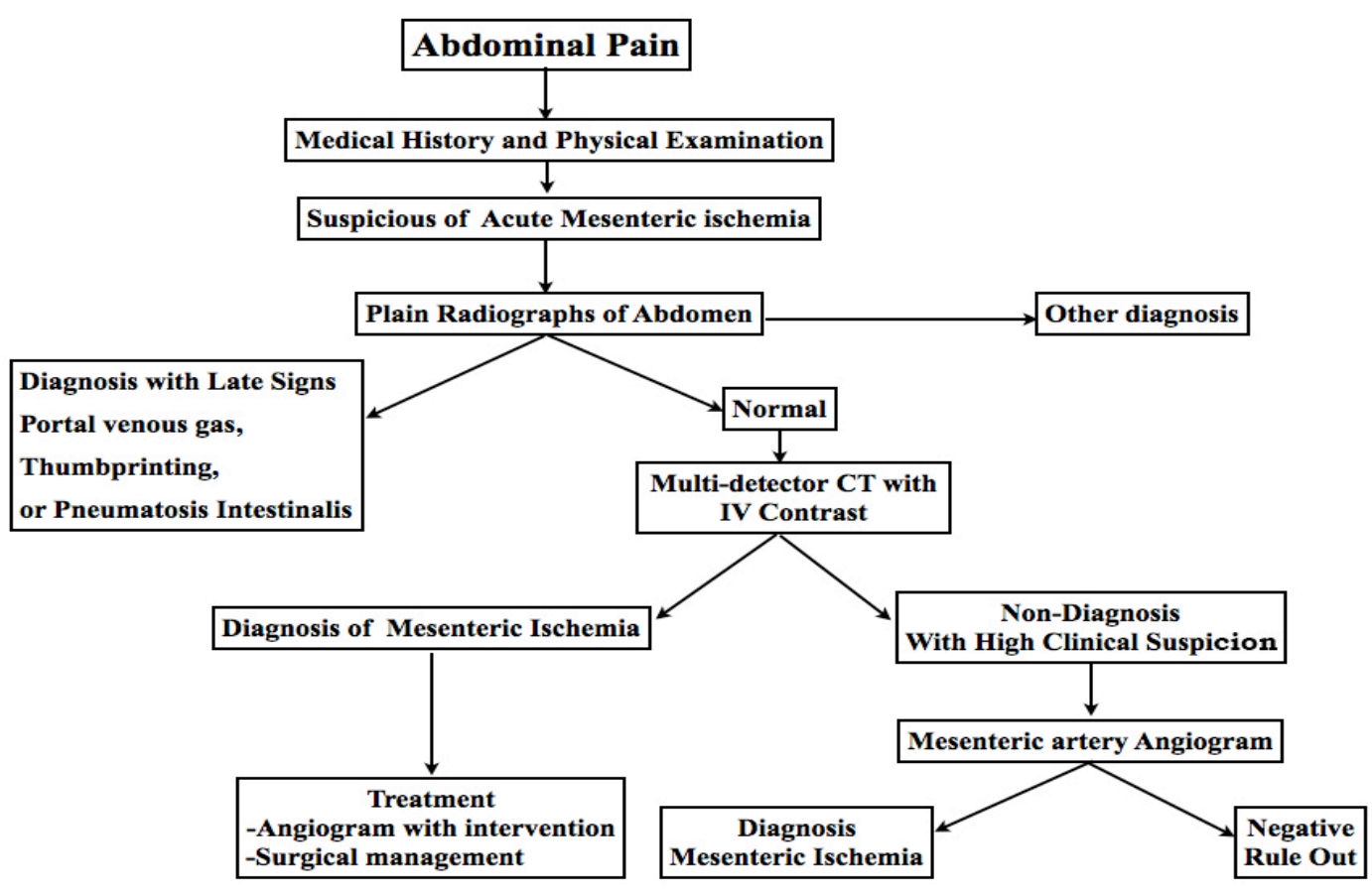

\section{KEY POINTS}

1. Patients with acute mesenteric ischemia need prompt diagnosis and treatment to decrease morbidity and mortality.

2. A high index of clinical suspicion is essential to make this diagnosis.

3. Laboratory results are non-specific and cannot make the diagnosis of AMI.
4. A high serum lactate should increase the clinical suspicion for AMI, but normal levels do not exclude this diagnosis.

5. MDCT is the best available noninvasive diagnostic test, is relatively safe, and has a high sensitivity and specificity.

KEY WORDS- ICU, abdominal imaging, sepsis, acute abdomen, and mesenteric ischemia 
Author Affiliation: Pantaree Aswanetmanee is an internal medicine resident at Faculty of Medicine Siriraj Hospital, Mahidol University in Thailand. Chok Limsuwat was an internal medicine resident at TTUHSC. Ariwan Rakvit is a gastroenterologist in the Department of Internal Medicine at TTUHSC.

Received: 4/2/2013

Accepted: 9/10/2013

Reviewers: Sharmila Dissanaike MD, Sreeram Parupudi MD

Published electronically: 10/15/2013

Conflict of Interest Disclosures: None

\section{REFERENCES}

1. Wall BF, Hart D. Revised radiation doses for typical Xray examinations. Report on a recent review of doses to patients from medical X-ray examinations in the UK by NRPB. National Radiological Protection Board. The British journal of radiology. 1997 May;70(833):437-9. PubMed PMID: 9227222.

2. Roszler MH. Plain film radiologic examination of the abdomen. Critical care clinics. 1994 Apr;10(2):277-96. PubMed PMID: 8012842.

3. Morrison J, Lucas N, Gravel J. The role of abdominal radiography in the diagnosis of intussusception when interpreted by pediatric emergency physicians. J Pediatr. 2009 Oct;155(4):556-9. PubMed PMID: 19560157.

4. Plewa MC. Emergency abdominal radiography. Emergency medicine clinics of North America. 1991 Nov;9(4):82752. PubMed PMID: 1915051.

5. Go HL, Baarslag HJ, Vermeulen H, Lameris JS, Legemate DA. A comparative study to validate the use of ultrasonography and computed tomography in patients with post-operative intra-abdominal sepsis. Eur J Radiol. 2005 Jun;54(3):383-7. PubMed PMID: 15899340.

6. Barkhausen J, Stoblen F, Dominguez-Fernandez E, Henseke P, Muller RD. Impact of CT in patients with sepsis of unknown origin. Acta Radiol. 1999 Sep;40(5):552-5. PubMed PMID: 10485247.

7. Kumta ND, Park G, Toms A, Housden B, Dixon AK. Body computed tomography in critically ill patients. Anaesthesia. 2002 Jun;57(6):544-8. PubMed PMID: 12010268.

8. Ahvenjarvi LK, Laurila JJ, Jartti A, Ylipalosaari P, AlaKokko TI, Syrjala HP. Multi-detector computed tomography in critically ill patients. Acta anaesthesiologica Scandinavica. 2008 Apr;52(4):547-52. PubMed PMID: 18261200.

9. Kim PK, Gracias VH, Maidment AD, O’Shea M, Reilly
PM, Schwab CW. Cumulative radiation dose caused by radiologic studies in critically ill trauma patients. J Trauma. 2004 Sep;57(3):510-4. PubMed PMID: 15454795.

10. Oldenburg WA, Lau LL, Rodenberg TJ, Edmonds HJ, Burger CD. Acute mesenteric ischemia: a clinical review. Arch Intern Med. 2004 May 24;164(10):1054-62. PubMed PMID: 15159262.

11. Yasuhara H. Acute mesenteric ischemia: the challenge of gastroenterology. Surgery today. 2005;35(3):185-95. PubMed PMID: 15772787.

12. Lee SS, Park SH. Computed tomography evaluation of gastrointestinal bleeding and acute mesenteric ischemia. Radiologic clinics of North America. 2013 Jan;51(1):29-43. PubMed PMID: 23182506.

13. Mazzei MA, Mazzei FG, Marrelli D, Imbriaco G, Guerrini $\mathrm{S}$, Vindigni $\mathrm{C}$, et al. Computed tomographic evaluation of mesentery: diagnostic value in acute mesenteric ischemia. J Comput Assist Tomogr. 2012 Jan-Feb;36(1):1-7. PubMed PMID: 22261763.

14. Hirsch AT, Haskal ZJ, Hertzer NR, Bakal CW, Creager MA, Halperin JL, et al. ACC/AHA 2005 Practice Guidelines for the management of patients with peripheral arterial disease (lower extremity, renal, mesenteric, and abdominal aortic): a collaborative report from the American Association for Vascular Surgery/Society for Vascular Surgery, Society for Cardiovascular Angiography and Interventions, Society for Vascular Medicine and Biology, Society of Interventional Radiology, and the ACC/AHA Task Force on Practice Guidelines (Writing Committee to Develop Guidelines for the Management of Patients With Peripheral Arterial Disease): endorsed by the American Association of Cardiovascular and Pulmonary Rehabilitation; National Heart, Lung, and Blood Institute; Society for Vascular Nursing; TransAtlantic Inter-Society Consensus; and Vascular Disease Foundation. Circulation. 2006 Mar 21;113(11):e463-654. PubMed PMID: 16549646.

15. Chang RW, Chang JB, Longo WE. Update in management of mesenteric ischemia. World J Gastroenterol. 2006 May 28;12(20):3243-7. PubMed PMID: 16718846.

16. Boley SJ, Sprayregen S, Veith FJ, Siegelman SS. An aggressive roentgenologic and surgical approach to acute mesenteric ischemia. Surgery annual. 1973;5:355-78. PubMed PMID: 4602220.

17. Mansour MA. Management of acute mesenteric ischemia. Arch Surg. 1999 Mar;134(3):328-30; discussion 31. PubMed PMID: 10088579.

18. May LD, Berenson MM. Value of serum inorganic phosphate in the diagnosis of ischemic bowel disease. Am J Surg. 1983 Aug;146(2):266-8. PubMed PMID: 6881453.

19. Tseng YC, Tseng CK, Chou JW, Lai HC, Hsu CH, Cheng $\mathrm{KS}$, et al. A rare cause of mesenteric ischemia: celiac axis compression syndrome. Intern Med. 2007;46(15):1187-90. 
PubMed PMID: 17675767.

20. Lund EC, Han SY, Holley HC, Berland LL. Intestinal ischemia: comparison of plain radiographic and computed tomographic findings. Radiographics : a review publication of the Radiological Society of North America, Inc. 1988 Nov;8(6):1083-108. PubMed PMID: 3205930.

21. Wolf EL, Sprayregen S, Bakal CW. Radiology in intestinal ischemia. Plain film, contrast, and other imaging studies. Surg Clin North Am. 1992 Feb;72(1):107-24. PubMed PMID: 1731379.

22. Horton KM, Fishman EK. Multi-detector row CT of mesenteric ischemia: can it be done? Radiographics : a review publication of the Radiological Society of North America, Inc. 2001 Nov-Dec;21(6):1463-73. PubMed PMID: 11706217.

23. Lee SS, Park SH. Computed tomography evaluation of gastrointestinal bleeding and acute mesenteric ischemia. Radiol Clin N Am 2013; 51: 29-43. PubMed PMID 23182506

24. Wiesner W, Mortele KJ, Glickman JN, Ji H, Ros PR. Pneumotosis intestinalis and portommesenteric venous gas in intestinal ischemia: correlation of CT findings with severity of ischemia and clinical outcome. Am J Rad 2001; 177 : 1319-1323. PubMed PMID 11717075

25. Wiesner W. [Is multidetector computerized tomography currently the primary diagnostic method of choice in diagnostic imaging of acute intestinal ischemia?]. Praxis. 2003 Jul 30;92(31-32):1315-7. PubMed PMID: 12934341. Ist die Multidetektor-Computertomographie heutzutage die primare Abklarunsgmethode der Wahl in der bildgebenden Diagnostik der akuten Darmischamie?

26. Kirkpatrick ID, Kroeker MA, Greenberg HM. Biphasic CT with mesenteric CT angiography in the evaluation of acute mesenteric ischemia: initial experience. Radiology. 2003 Oct;229(1):91-8. PubMed PMID: 12944600.

27. McLeod R, Lindsay T, O’Malley M. Evidence Based Reviews in Surgery Group. Canadian Association of General Surgeons and American College of Surgeons evidence based reviews in surgery. 15. Biphasic CT with mesenteric CT angiography in the evaluation of acute mesenteric ischemia: initial experience. Canadian journal of surgery 2005 Dec;48(6):491-3. PubMed PMID: 16417057.

28. Tambyraja AL. Management of acute mesenteric ischaemia: recommended strategy is misleading. BMJ. 2003 Aug 16;327(7411):396; author reply PubMed PMID: 12920014. Pubmed Central PMCID: 1126813.

29. Ward D, Vernava AM, Kaminski DL, Ure T, Peterson $\mathrm{G}$, Garvin P, et al. Improved outcome by identification of high-risk nonocclusive mesenteric ischemia, aggressive reexploration, and delayed anastomosis. Am J Surg. 1995 Dec;170(6):577-80; discussion 80-1. PubMed PMID: 7492004.
30. Deehan DJ, Heys SD, Brittenden J, Eremin O. Mesenteric ischaemia: prognostic factors and influence of delay upon outcome. Journal of the Royal College of Surgeons of Edinburgh. 1995 Apr;40(2):112-5. PubMed PMID: 7776272.

31. Christensen MG, Lorentzen JE, Schroeder TV. Revascularisation of atherosclerotic mesenteric arteries: experience in 90 consecutive patients. European journal of vascular surgery. 1994 May;8(3):297-302. PubMed PMID: 8013680. 